\title{
Inferior Canaliculi Punctal Granuloma of the Lacrimal System: A Case Report
}

\author{
Nur Aqilah $S^{1}$, Farizal $A^{2}$, Othmaliza $\mathrm{O}^{3}(\bowtie)$ \\ Department of Ophthalmology, Faculty of Medicine, Universiti Kebangsaan Malaysia Medical Centre, \\ Jalan Yaacob Latif, Bandar Tun Razak, 56000 Cheras, Kuala Lumpur, Malaysia.
}

\begin{abstract}
Pyogenic granuloma of the eyes usually occurs after ocular surgery or inflammation related to the eyes, itself. This lesion is commonly related to procedures associated with chalazia, strabismus, or even enucleation. However, the incidence of pyogenic granuloma that arises directly from the lower canaliculi of the nasolacrimal system is rare and not being extensively reported. We report a case of an elderly lady who presented with pyogenic granuloma post EDCR with silicone stenting for left nasolacrimal duct obstruction. She presented with persistent left eye epiphora following procedure. The unusual site for pyogenic granuloma and it occurrence after EDCR raise the possibility that the condition is related to previous procedure and the material being used.
\end{abstract}

Keywords: dacryocystorhinostomy, epiphora, lacrimal duct obstruction, pyogenic granuloma, silicone elastomer

\section{Correspondence:}

Othmaliza Othman, Department of Ophthalmology, Faculty of Medicine, Universiti Kebangsaan Malaysia Medical Centre, Jalan Yaacob Latif, Bandar Tun Razak, 56000 Cheras, Kuala Lumpur, Malaysia. Tel: +60391455982 Fax: +60391456673 Email: drlizasaha@yahoo.com

\section{Introduction}

The term "pyogenic granuloma” does not reflect its true histopathological appearance. It is a lobular capillary hemangioma and this separates it from other malignant vascular tumors (1). The exact etiology is usually obscured. It usually results from previous history for chalazion and its surgery, other ocular or adnexal surgery and accidental trauma. Only 4 out of 20 cases of pyogenic granuloma reported to occur after surgery involving the nasolacrimal system (2). In another local report, granuloma formation after EDCR with silicone stent insertion was $15.4 \%$ while no granuloma formation noted post EDCR without insertion of silicone stent (3).

Pertaining to the eye, the most common site of pyogenic granuloma would be the conjunctiva. It is rare and literature hardly described pyogenic granuloma occurring within the lacrimal drainage system where it can cause persistent epiphora due to obstruction and inflammation (4). In this case, the patient had history of probing, EDCR, and silicone intubation of the lacrimal passages which raises the likelihood of the formation of pyogenic granuloma through inflammatory process. Literature also mentioned that pyogenic granuloma of the lacrimal system was more prevalence in women than in men the ratio being 1:3 and usually affecting women more than 40 years old of age (5). This case illustrates pyogenic granuloma formation involving the nasolacrimal passages that occurred after EDCR and silicone intubation.

\section{Case Report}

An 81-year-old, elderly lady presented with chronic persistent epiphora over the left eye for 4 months after she had undergone endoscopic dacryocystorhinostomy (EDCR) procedure for nasolacrimal duct obstruction. She did not seek any medical attention prior to this as she contributed these symptoms to dry eye. 
Upon presentation, ocular examination revealed bilateral pseudophakia with good visual acuity of 6/9 and near vision of N8 bilaterally. However, examination over the left eye revealed erythematous periocular skin with clear watery discharge. There was an outpouching of pink, fleshy, and vascularized tissue that appeared to be arising directly from the punctum of the lower canaliculi (Fig. 1). The tissue outgrowth was small measuring about $5 \mathrm{~mm} \times 5 \mathrm{~mm}$ in dimension.

Examination of the ocular adnexa over the left eye was normal. There were no signs of blepharitis or meibomian gland dysfunction. Anterior segment examination noted that the left conjunctiva appeared to be injected while the cornea has multiple punctate epithelial keratopathy indicating dryness of the eye. No sign of uveitis and posterior segment examination was normal.

Patient was treated with topical steroid four times per day and ointment steroid to be applied at night. Prompt referral to ENT colleague was made in view of her previous history of ENT surgery and for nasal endoscopy to look for origin of the mass as clinically it appeared to arise directly from the punctum. Nasal endoscopy revealed no abnormalities such as adhesions or synechiae and nasal douching was done for this patient. The granuloma still persisted after six weeks of therapy and she subsequently underwent snip procedure under local anesthesia. The tissue was sent for histopathological examination (HPE) and diagnosis of pyogenic granuloma was confirmed (Fig. 2).

\section{Discussion}

In patient with persistent epiphora, one of the surgical treatment options is endoscopic dacryocystorhinostomy (EDCR). Ocular complications after EDCR can occur but it is usually rare.

Among the complications are punctum polyps, punctum erosion, canalicular obstruction secondary to scarring, conjunctival fistula and retrobulbar hemorrhage. We reported a case of an elderly lady who initially presented to opthalmology clinic with chronic persistent epiphora. She was subsequently referred to ENT colleague and was then subjected to EDCR. During the procedure, a silicone tube was inserted as a stent and remained in situ for one week, postoperatively.

In EDCR, usage of silicone tube as a stent is controversial and debatable (6). Recent study showed that routine silicone intubation during EDCR had no added benefit when compared with EDCR without

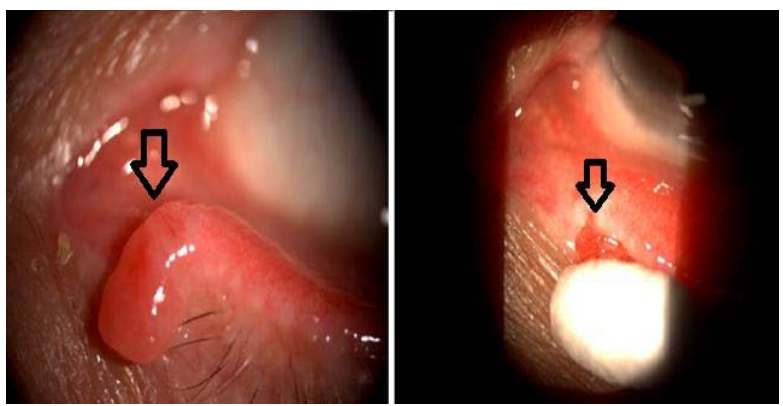

Figure 1: Fleshy, pedunculated mass that arises directly from the punctum of the lower canaliculi.

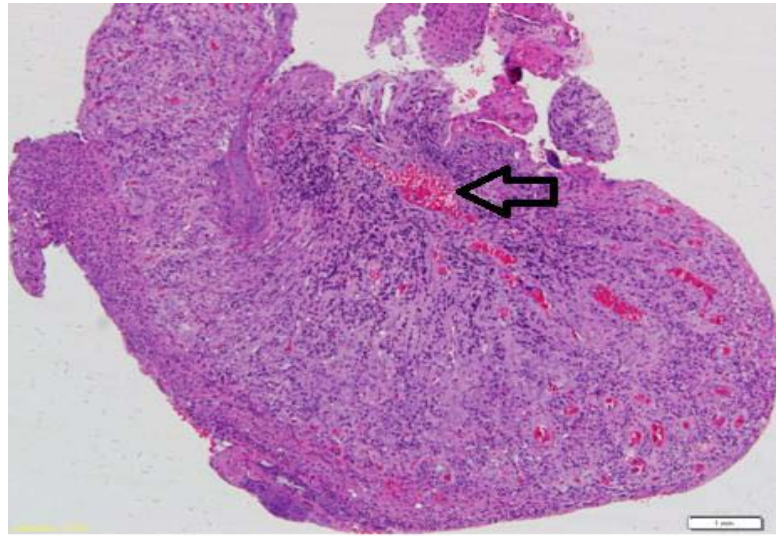

Figure 2: Microscopic examination revealed ulcerated surface lining lobules of proliferated capillary sized vessels. Stroma is heavily infiltrated by acute and chronic inflammatory cells (H\&E; magnification x100).

silicone intubation $(7,8)$. It had also been noted that punctual granuloma being one of the complications for EDCR apart from other common causes such as synechiae, sump syndrome, and epistaxis (7). A study stated that pyogenic granuloma occurred in one out of twenty patients after silicone intubation (8). This number showed that the occurrence of pyogenic granuloma is one of the rare complications of silicone intubation. Another study reported two cases presented with inflammatory masses after dacyocystorhinostomy with silicone tubes retention. It is postulated that the inflammatory masses occurred as a result of irritation caused by the knots and cut end of the silicone tubing in the lacrimal passages (9).

It is important to exclude the possibility of retained silicone material when a patient with history of lacrimal surgery presented with granuloma. Granuloma and retained material could lead to obstruction and subsequently, failure of the initial procedure. It can also incite vicious cycle of recurrent inflammation and secondary infection which can further compromised patient ocular status. In EDCR, silicone tube usually remained in situ for average of three to six months. As for this patient, the silicone 
tube was removed one week after operation. Despite early removal of the tube, granuloma still arises from the punctum.

The peculiar location of the granuloma arising from the lower punctum makes it difficult to be detected earlier on cursory examination. It has a tendency to be retracted back inward toward the lower canaliculi and hence might not be detected. Furthermore, patient did not seek treatment earlier as she attributed the persistent epiphora after operation to dry eye. Hence, in this case, it is important for early detection and patient education as the symptoms, although seemed trivial can be debilitating and reduced patient's quality of life. It is also important for patient to have ophthalmological assessment after lacrimal procedure to detect ocular complications related to EDCR that can happen.

This patient underwent snip procedure only after 6 weeks from initial presentation. She was treated earlier with topical steroid. The decision to surgically excise the granuloma in this patient should be made earlier as the granuloma would not respond to steroid therapy. This was because it was not the typical conjunctival pyogenic granuloma that wills involutes and has good respond to topical steroid. Furthermore, prolonged steroid therapy can expose patient to higher risk of developing secondary glaucoma.

Apart from eDCR, there were also reports about pyogenic granuloma occurring after silicone intracanalicular plugs usage for the treatment of severe dry eyes $(10,11)$. It stated that pyogenic granuloma occurring as a result of chronic irritation leading to granuloma formation (10). Specific foreign body tissue reaction such as asteroid bodies, refractile particles that are non birefringent and multinucleated giant cells had been noted to occur after the insertion of silicone elastomer tubes $(12,13)$.

\section{Conclusion}

Pyogenic granuloma is one of the complications that are known to occur after procedure related to the nasolacrimal passageway. However, being common as it is, it is not being extensively studied or reported. By reporting the incidence and occurrence of pyogenic granuloma after certain procedure, it can help surgeon to choose the methods and material before each procedure involving the nasolacrimal system. Improvement and modifications of surgical techniques can be implemented to reduce the occurrence of pyogenic granuloma which can pose a troublesome symptom for the patient.

\section{References}

1. Kapadia SB, Heffner DK. Pitfalls in the histopathologic diagnosis of pyogenic granuloma. Eur Arch Otorhinolaryngol 1992; 249(4): 195-200.

2. Ferry AP. Pyogenic granuloma of the eye and ocular adnexa: a study of 100 cases. Trans Am Ophthal Soc 1989; 87: 327-43.

3. Evelyn Tai LM, Jessica MPT, Wan Hazabbah WH, Ramiza R, Baharudin A, Adil H. Effect of stenting and mucosal flap preservation on outcome of endoscopic dacryocystorhinostomy. Guoji Yanke Zazhi (Int Eye Sci) 2014; 14(3): 381-5.

4. Asiyo MN, Stefani FH. Pyogenic granuloma of the lacrimal sac. Eye (Lond) 1992; 6(Pt 1): 97101.

5. Traquair HM. Chronic dacryocystitis, its causation and treatment. Arch Ophthalmol 1941; 26(2): 165-80.

6. de Souza C, Nissar J. Experience with endoscopic dacryocystorhinostomy using four methods. Otolaryngol Head Neck Surg 2010; 142(3): 389-93.

7. Rahman SH, Tarafder KH, Ahmed MS, Saha KL, Tariq A. Endoscopic dacryocystorhinostomy. Mymensingh Med J 2011; 20(1): 28-32.

8. Feng YF, Cai JQ, Zhang JY, Han XH. A metaanalysis of primary dacryocystorhinostomy with and without silicone intubation. Can J Ophthalmol. 2011; 46(6): 521-7.

9. Dresner SC, Codère $\mathrm{F}$, Brownstein S, Jouve $\mathrm{P}$. Lacrimal drainage system inflammatory masses from retained silicone tubing. Am J Ophthalmol 1984; 98(5): 609-13.

10. Kim BM, Osmanovic SS, Edward DP. Pyogenic granulomas after silicone punctal plugs: a clinical and histopathologic study. Am J Ophthalmol 2005; 139(4): 678-84.

11. Akova YA, Demirhan B, Cakmakçi S, Aydin P. Pyogenic granuloma: a rare complication of silicone punctal plug. Ophthalmic Surg Lasers 1999; 30(7): 584-5. 
12. Krayenbuhl BH, Panizzon RG. Silicone granuloma. Dermatology 2000; 200(4): 360-2.

13. Ficarra G, Mosqueda-Taylor A, Carlos R. Silicone granulomaof the facial tissues: a report of seven cases. Oral Surg Oral Med Oral Pathol Oral Radiol Endod 2002; 94(1): 65-73. 